\title{
Non-traditional and hybrid processes for micro and nano manufacturing
}

\author{
Atanas Ivanov $^{1} \cdot$ Kai Cheng ${ }^{1}$ \\ Published online: 25 November 2019 \\ (C) Springer-Verlag London Ltd., part of Springer Nature 2019
}

This editorial is for collating the special issue on nontraditional and hybrid processes for micro and nano manufacturing, based on stringently selected and extended papers presented at the International Conference on Nanomanufacturing on 4-6 July 2018 at Brunel University London. All papers selected were undertaken the thorough review process through the journal review system, there are 16 papers finally included in this issue.

Micro and nano manufacturing has become a key valueadded enabling technology for the modern advanced manufacturing. Micro and nano manufacturing technologies are widely spread out now in many sectors of the engineering industry and enjoy the interest not only of the researchers but also rapidly growing interest from the high-tech industries in particular. More and more micro and nano technologies reach their maturity and become part of the industrially used technologies in batch and mass production of micro and nano components, devices, products and systems. Commercial advantages of employing these new emerging manufacturing technologies are that this may enable the company a kick-start on securing specific micro/nano niche in the market place and secure high value-added profit before any other player decides to adopt similar approach.

Non-traditional and hybrid processes are known for quite some time but they were often limited in the hands of researchers and developers and companies falling in a specific targeted market. With the growing demand for micro and nano systems on the market, they are increasingly finding their natural fields of applications and starting to enjoy rapid growth not only as R\&D tools but

Kai Cheng

kai.cheng@brunel.ac.uk

1 Brunel University London, Uxbridge, UK also as real industry applicable means for manufacturing micro and nano engineering devices, products and systems.

The focus of this special issue is on the development and challenges in association with the emerging products and new manufacturing technologies in the field. As usual, the main products were related to microfluidic systems, micro actuators, micro optics and MEMS. Here the design requirements have to meet the process capability in order to have successful products on the market. It is very important that majority of the papers had a specific targeted market or even a product and being developed to fulfil the requirements of that specific product and application, which can provide more objective future directions and case studies for precision engineering research community and the industry. Maybe in the future, we have to allow the product to dictate the process parameters and the fully integrated hybrid processes and machines to be tuned and developed for the production of that particular product and alternatives. One of the main challenges in employing such manufacturing systems is the complexity and interdisciplinary knowledge needed to run such processes on an industrial scale. This additionally renders demand to the engineering companies to employ high calibre specialists in order to be able to utilise and benefit from applying such technologies. Furthermore, material science also plays a vital role in the development of the non-traditional and hybrid processes and it is an inseparable part of the enabling technology.

It is pleasing to see the 16 papers included have all attempted to exploit the opportunity of producing micro and nano devices, products and systems using different sorts of materials. The papers reflect the state-of-the-art in the field and attempt the challenges described above. The issue has fulfilled the original objectives to some extent. We hope that those papers will provide some insight for future research and development particularly against specific precision engineering products. We also hope it will provide good reference for industrial practices. 
Nevertheless, those papers included are also expected to provide a stimulus for whom being interested and involved in micro/nano manufacturing science and technology to further develop innovative processes, machines and systems, and continue their exploratory journey in the field.
This special issue has been made possible by joint efforts from Igan Dagoy, Silvia Schilgerius and Mary Kimberly Anne Campos at the Springer Nature support office. We would like to thank them for their kindly efforts, support and patience throughout the process. 